\title{
A novel predict factor that increases the success rate of methotrexate treatment in fallopian tube pregnancy
}

\author{
Qin Lin", Nan Lin", Gongli Wang, Xuan Zheng*, Renyi Hua*^ \\ International Peace Maternity and Child Health Hospital of China Welfare Institution (IPMCH), School of Medicine, Shanghai Jiao Tong \\ University, Shanghai Key Laboratory of Embryo Original Diseases, Shanghai Municipal Key Clinical Specialty, Shanghai, China \\ Contributions: (I) Conception and design: Q Lin, X Zheng; (II) Administrative support: G Wang, X Zheng; (III) Provision of study materials or \\ patients: R Hua, Q Lin; (IV) Collection and assembly of data: N Lin, Q Lin; (V) Data analysis and interpretation: R Hua, N Lin; (VI) Manuscript \\ writing: All authors; (VII) Final approval of manuscript: All authors. \\ "These authors contributed equally to the paper and are joint first authors. \\ *These authors contributed equally to the paper and are joint correspondent authors. \\ Correspondence to: Xuan Zheng; Renyi Hua. International Peace Maternity and Child Health Hospital of China Welfare Institution, 910 Heng Shan \\ Road, Shanghai 200050, China. Email: rovilas@163.com; renyi3551_cn@me.com.
}

\begin{abstract}
Background: For stable fallopian tube pregnancy (FTP), methotrexate (MTX) therapy is reported to be as effective as laparoscopy. However, some cases would need further treatment, e.g., another dose of MTX or laparoscopy. This study is to investigate the potential factors during the treatment of FTP that may facilitate the prediction of a successful outcome of MTX therapy.

Methods: All FTP cases admitted to the International Peace Maternal and Child Health Hospital (IPMCH), Shanghai, China from January 2016 to December 2017 were reviewed. All patients received a single dose of $50 \mathrm{mg} / \mathrm{m}^{2}$ MTX prior to other treatment. Statistical analysis was performed to determine the correlation between clinical parameters and the success rate of MTX treatment.

Results: The success rate of single-dose MTX was $77.53 \%$. The serum beta-human chorionic gonadotropin ( $\beta$-hCG) level cut-off value was $452.64 \mathrm{IU} / \mathrm{L}$, with a specificity of $76.7 \%$ and sensitivity of $43 \%$ [area under the receiver operating characteristic curve (AUC) $0.803 ; \mathrm{P}<0.0001$ ]. In addition, serum $\beta$-hCG levels and patient age correlated with the success rate of MTX treatment.

Conclusions: Lower $\beta$-hCG levels led to successful MTX treatment for FTP, with a cutoff value of 452.64 IU/L. Younger patients were more sensitive to MTX treatment. These results may help clinicians when deciding the potential therapy for patients with tubal ectopic pregnancies.
\end{abstract}

Keywords: Fallopian tube pregnancy (FTP); ectopic pregnancy (EP); methotrexate; beta-human chorionic gonadotropin ( $\beta$-hCG)

Submitted Nov 15, 2020. Accepted for publication Jan 15, 2021.

doi: 10.21037/atm-20-7914

View this article at: http://dx.doi.org/10.21037/atm-20-7914

\section{Introduction}

An ectopic pregnancy (EP) is defined as a pregnancy that occurs outside the uterine cavity. The incidence of EP is 27 per 1,000 pregnancies (1). There are different types of EPs, with fallopian tube pregnancy (FTP) being the most common which mainly due to abnormal structure of fallopian tube. Elevated level of serum $\beta$-hCG combined with ultrasound findings can accurately diagnose EP in most patients. Clinical diagnosis of a suspected FTP is by transvaginal ultrasonography and an increased level of

^ ORCID: 0000-0002-6556-737X. 
serum $\beta$-hCG.

Besides unstable FTPs, most FTPs can be treated with either minimally invasive surgery, or injections of methotrexate (MTX), which is widely used due to its effectiveness and minimal side-effects. The contraindications for MTX are consistent across different practice bulletins from several obstetrics and gynecology associations, and include hemodynamic instability, fetal cardiac activity, and $5,000 \mathrm{mIU} / \mathrm{mL}$ or higher of $\beta$-hCG (2-4). However, several studies showed that in progressing EPs, the success rate of MTX is lower than other studies reported in the literature (5).

For stable FTPs, MTX therapy is reported to be as effective as laparoscopy (6). However, some of our patients needed a second dose of MTX or laparoscopy since their condition progressed to be advanced (e.g., the serum $\beta$-hCG levels did not decrease or continued internal bleeding of the tubal pregnancy) after the first dose of MTX. It is agreed upon that serum $\beta$-hCG level is one of the most important risk factors associated with the treatment failure of singledose MTX $(7,8)$. The aim of our study was to investigate other potential factors during the treatment of FTP that may facilitate the prediction of a successful outcome with MTX therapy. We provided a cut-off point value of $\beta$-hCG level and demonstrated that serum $\beta$-hCG levels and patient age correlated with the success rate of MTX treatment. We present the following article in accordance with the STARD reporting checklist (available at http://dx.doi.org/10.21037/ atm-20-7914).

\section{Methods}

\section{Patients}

We reviewed all the FTP cases admitted to the International Peace Maternal and Child Health Hospital (IPMCH), Shanghai, China from January 1, 2016 to December 31, 2017. The Ethics Committee of the IPMCH approved this study (No. 2013-6). Patients who received a single dose of $50 \mathrm{mg} / \mathrm{m}^{2}$ MTX prior to other treatments were included in this study. Their medical histories, serum $\beta$-hCG levels before MTX treatment, size of the mass as observed by transvaginal ultrasonography, and treatment regimens following the first dose of MTX were collected. After MTX therapy, serum $\beta$-hCG was measured at 1,4 , and 7 days after the injection. Success of the treatment was calculated statistically. All procedures performed in this study involving human participants were in accordance with the Declaration of Helsinki (as revised in 2013). Individual consent for this retrospective analysis was waived.

\section{Statistical analysis}

Successful treatment was defined as a decrease in the levels of $\beta$-hCG by at least $15 \%$ from day 4 to day 7 after MTX administration. A Spearman's test was used to evaluate the distribution of the data. Area under the receiver operating characteristic (ROC) curve and maximal Euclidean and Youden's indexes were included in the statistical analysis to determine the cutoff value of $\beta$-hCG during MTX treatment. Sensitivity and specificity were calculated according to the Youden's index (sensitivity + specificity -1 ). Statistical analysis was performed with SPSS 20.0 software (SPSS Inc., Chicago, IL, USA) and $\mathrm{P}<0.05$ was considered statistically significant.

\section{Results}

\section{Baseline characteristics}

From January 1, 2016 to December 31, 2017, there were 267 clinically diagnosed FTP patients who received single dose MTX therapy as their primary treatment. A total of 60 patients failed to respond adequately to the first dose of MTX. Of these patients, 42 were subsequently subjected to laparoscopy, and 18 were given another dose of MTX (15 had a further single dose and 3 had multiple doses of MTX) since their serum $\beta$-hCG did not decrease adequately or even increased after the first dose (Figure 1). One patient had a complication related to intrauterine adhesions after MTX therapy.

\section{Effectiveness of MTX on fallopian tube pregnancy}

The success rate for using 1 dose of MTX was $77.53 \%$. Serum $\beta$-hCG before MTX treatment was $469.12 \pm$ 421.61 IU/L. By performing a nonparametric Spearman's correlation rank coefficient, it was found that the initial level of serum $\beta$-hCG was correlated to the success rate, as seen in the previous literature (Figure $2 ; \mathrm{r}=-0.6740, \mathrm{P}<0.05$ ). The median serum $\beta$-hCG level in the group with a successful MTX therapy outcome was initially 406.47 IU/L, whereas in the group that had unsuccessful MTX treatment, the median was 947.13 IU/L (Figure 3; $\mathrm{P}<0.0001$ ).

\section{The relationship of serum $\beta-b C G$ level with MTX therapy}

We used an ROC curve to determine a cut-off value of serum $\beta$-hCG level, which can be used as a predictor for successful MTX therapy. The area under the curve was 


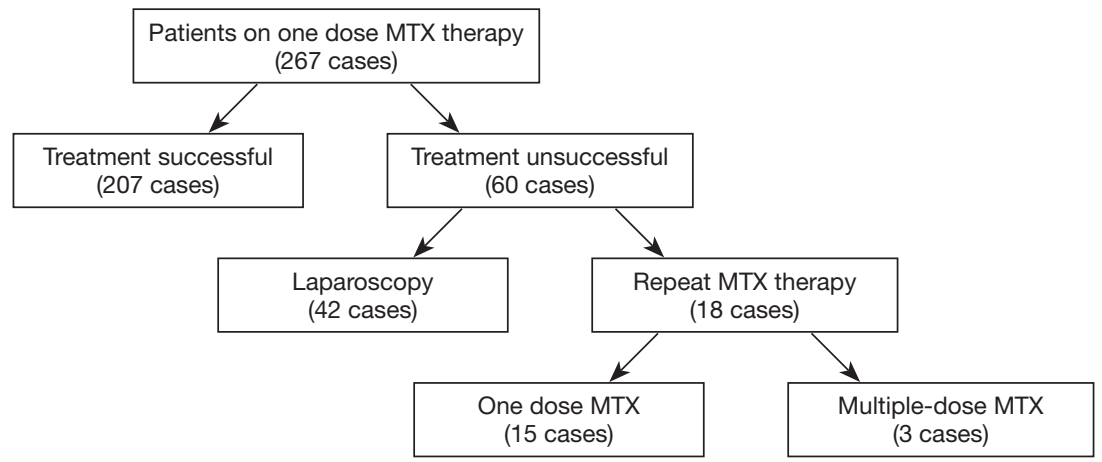

Figure 1 A flow chart showing the patients in the study. MTX, methotrexate.

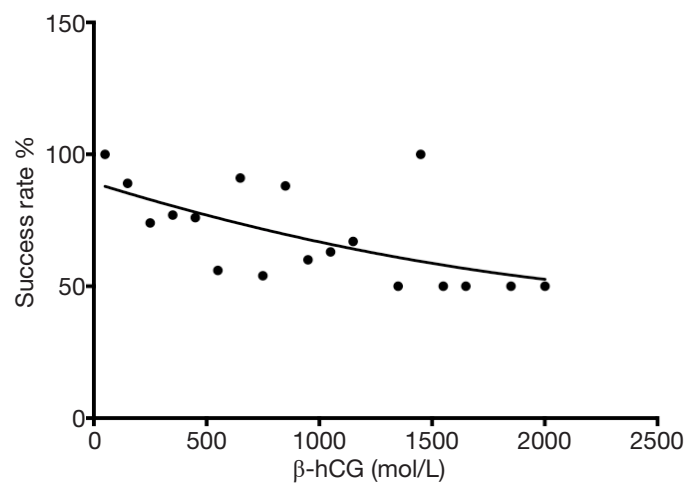

Figure 2 Each point represents the average success rate for the respective levels of beta-human chorionic gonadotropin ( $\beta$-hCG). An estimation of the success rate of methotrexate (percentage) according to $\beta$-hCG level can then be determined. Correlation coefficient, $\mathrm{r}=-0.6740, \mathrm{P}<0.05$.

calculated to evaluate the overall prognostic performance of the serum $\beta$-hCG level. On the ROC curve, each point represents the sensitivity and specificity corresponding to a particular cut-off value. We defined the sensitivity as the fraction of patients who failed to respond to the drug, and specificity as the fraction of those who were successful with the MTX therapy. The point of the maximal Youden's index and the point of the minimal Euclidian distance to the top left edge of the graph were calculated (Table 1). This analysis showed a statistically significant area under the curve of 0.803 , with a standard error of 0.031 and $\mathrm{P}<0.0001$ (95\% CI: $0.743,0.863)$. The subsequent application of minimal Euclidean distance and maximal Youden's index both calculated the serum $\beta$-hCG level cut-off value of $452.65 \mathrm{IU} / \mathrm{L}$, with a specificity of $76.7 \%$ and sensitivity of $43 \%$ (Figure 4).

\section{Other factors associated with the success rate of MTX therapy}

We analyzed size of the FTP by transvaginal ultrasonography. The mean size of the FTP was $22.33 \pm 7.97 \mathrm{~mm}$. The nonparametric Spearman's rank correlation coefficient between the size and the success rate of 1 dose of MTX was not statistically significant (Figure 5; $\mathrm{r}=-0.8208, \mathrm{P}=0.0667$ ). However, there was a trend such that the smaller the FTP, the better the outcome. The mean age of the patients was $31.70 \pm 4.81$ years, and it was found that age was significantly correlated with the success rate of MTX therapy (Figure 6; $\mathrm{r}=-1, \mathrm{P}=0.0083$ ).

\section{Discussion}

In this study, we found that lower $\beta$-hCG levels led to successful MTX treatment for FTP, with a cutoff value of $452.64 \mathrm{IU} / \mathrm{L}$. Furthermore, younger patients were more sensitive to MTX treatment. The aim of this study was to identify potential factors which could predict failure of MTX treatment. MTX is a classical therapy for EPs. Systemic MTX has been used to treat gestational trophoblastic disease since 1956 and was first used to treat EP in 1982 (9). There are three classical protocols for MTX treatment: a single dose, 2 doses, and multiple doses. Observational studies that compared the single-dose and multiple-dose regimens have indicated that although the multiple-dose regimen was statistically more effective, the single-dose regimen was associated with a decreased risk of adverse side-effects (10). However, a more recent systematic review of randomized controlled trials showed similar rates of success with the single-dose regimen compared with the multiple-dose regimens, accompanied by an increased risk 


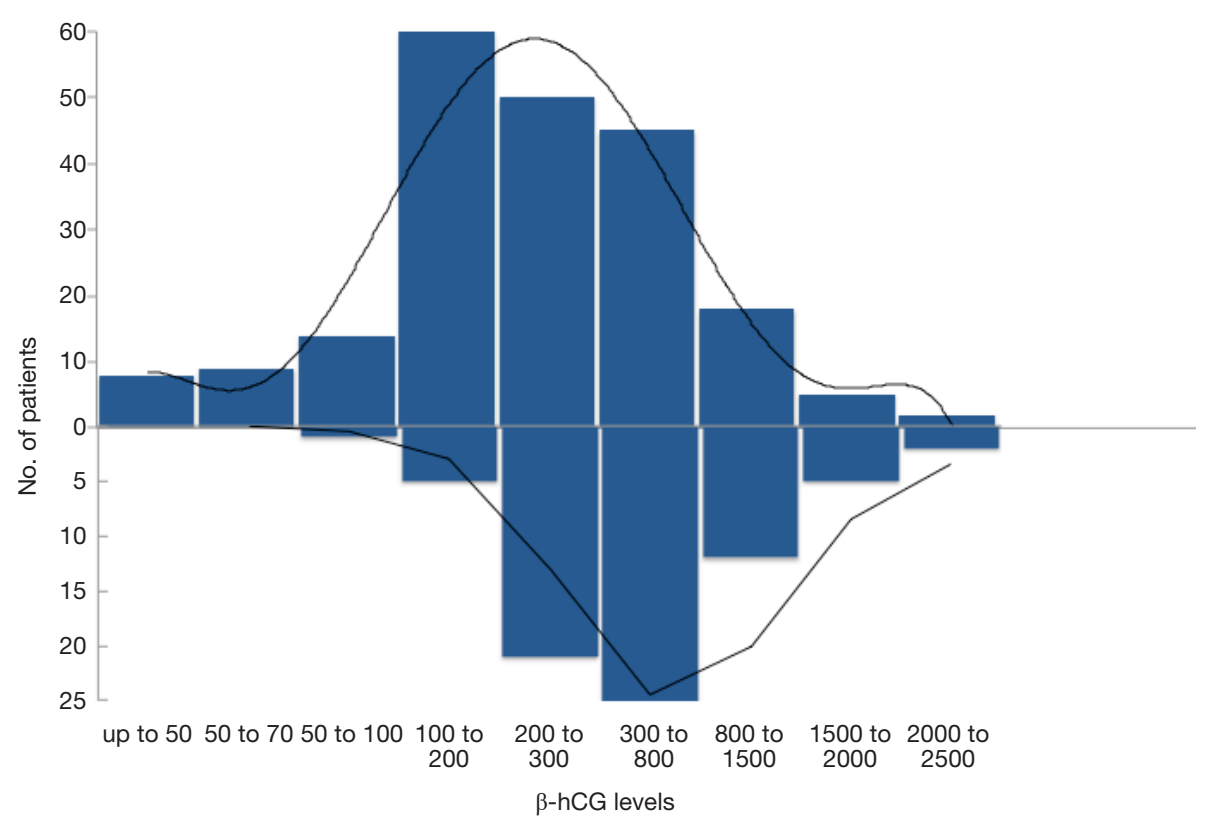

Figure 3 A comparison of the number of patients and beta-human chorionic gonadotropin ( $\beta$-hCG) levels with a successful and unsuccessful methotrexate (MTX) therapy outcome.

Table 1 Area under the curve for determination of successful methotrexate therapy in cases of fallopian tube pregnancies

\begin{tabular}{|c|c|}
\hline Statistics & Value \\
\hline Area & 0.803 \\
\hline Std. error ${ }^{\mathrm{a}}$ & 0.031 \\
\hline Asymptotic significance ${ }^{b}$ & 0 \\
\hline \multicolumn{2}{|c|}{ Asymptotic $95 \%$ confidence interval } \\
\hline Lower bound & 0.743 \\
\hline Upper bound & 0.863 \\
\hline
\end{tabular}

of adverse effects with the multiple-dose protocol (11). A meta-analysis which reviewed 26 case series found that the overall success rate of MTX was $89 \%$ (10). According to the clinical management guidelines of the American College of Obstetricians and Gynecologists (ACOG), the success rate of systemic MTX for the treatment of FTP is approximately $70-95 \%$ (3). At our hospital, the success rate for this therapy is $77.53 \%$.

Several reports have reiterated that serum $\beta$-hCG levels are closely related to the success rate of MTX treatment $(7,12)$.

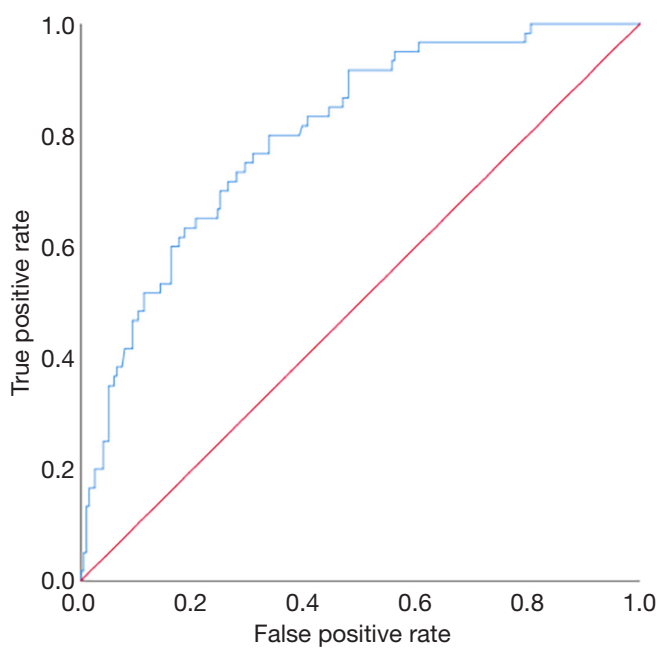

Figure 4 The ratios of the true and false positive rates as judged by the best serum beta-human chorionic gonadotropin ( $\beta$-hCG) cutoff value $(\mathrm{mIU} / \mathrm{mL})$ obtained.

The Royal College of Obstetricians and Gynaecologists (RCOG) state that women with a serum $\beta$-hCG below 3,000 IU/L and minimal symptoms are the most suitable for MTX therapy (4). A study that focused on the success rate of MTX therapy reported that the cut-off value of the initial serum $\beta$-hCG level was $2,121 \mathrm{mIU} / \mathrm{mL}$, 


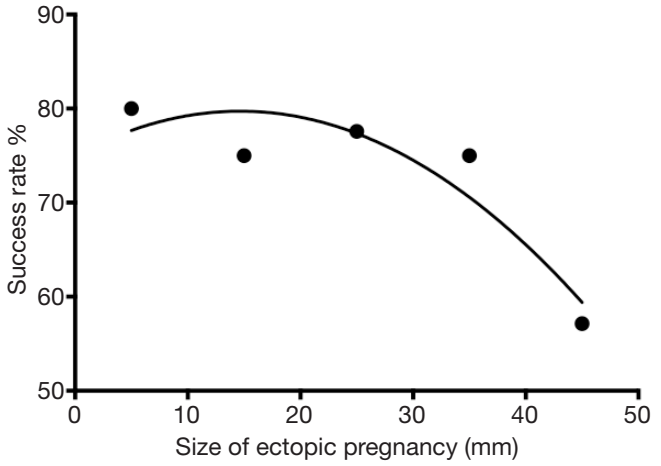

Figure 5 Each point represents the average success rate for the respective size of the fallopian tube pregnancy (FTP). With the equation, an estimation of the success rate of methotrexate treatment according to size of FTP can be made. Correlation coefficient, $\mathrm{r}=-0.8208, \mathrm{P}=0.0667$.

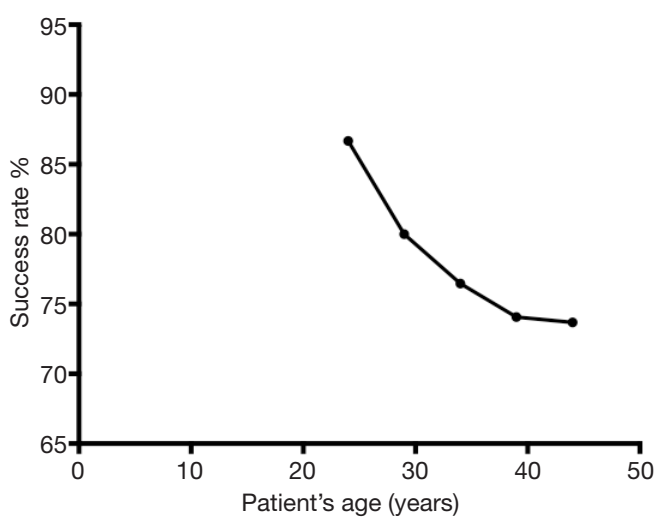

Figure 6 Each point represents the average success rate for the respective ages of the patients. With the equation, an estimation of the success rate of methotrexate treatment (percentage) according to patient's age can be made. Correlation coefficient, $r=-1$, $\mathrm{P}=0.0083$.

and $5.3 \%$ of patients who had an initial level below this value experienced failure. This compares to $43.3 \%$ of patients with an initial serum $\beta$-hCG level equal to or above $2,121 \mathrm{mIU} / \mathrm{mL}$ (13). In our study, $\beta$-hCG level correlated with the outcome of MTX therapy $(\mathrm{r}=-0.6740, \mathrm{P}<0.05)$. Serum $\beta$-hCG levels ranged from 28.3-2,145 IU/L. However, with serum $\beta$-hCG levels lower than $2,121 \mathrm{IU} / \mathrm{L}$, our failure rate was increased to $22.36 \%$. This result indicates that serum $\beta$-hCG is not the only factor influencing the outcome of MTX treatment. In our study, we concluded that patients with FTPs who presented with serum $\beta$-hCG levels above 452.65 lU/L have a significantly higher chance of MTX therapy failure.

EP greater than $4 \mathrm{~cm}$ in size as imaged by transvaginal ultrasonography is one of the contraindications to MTX therapy (3). In a previous study, which focused on the volume of the FTP, a clear tendency towards a lower volume was found in the successful MTX therapy group. However, a statistically significant correlation between a smaller volume of FTP and a better MTX therapy outcome could not be verified (14). We also compared the size of the FTP using transvaginal ultrasonography and the success rate of MTX, and our results were similar. There was a trend of correlation $(\mathrm{r}=-0.8208, \mathrm{P}=0.0667)$, but the results were not significant.

It has also been shown that the age of patients is not significantly correlated with the success rate of MTX treatment $(15,16)$. However, in this study, we found a good correlation between age and outcome of MTX therapy $(\mathrm{r}=-1, \mathrm{P}=0.0083)$. In cases of primary central nervous system lymphoma, a successful outcome of MTX therapy, as determined by the area under the curve $\left(\mathrm{AUC}_{\mathrm{MTX}}\right)$, was significantly correlated with age (17).

In conclusion, a single intramuscular injection of MTX has become the main treatment for FTP because it is a safe and effective alternative to surgery for patients who are not expected to experience tubal rupture. This applies to patients with $\beta$-hCG levels less than $2,000 \mathrm{mIU} / \mathrm{mL}$, especially less than $452.65 \mathrm{IU} / \mathrm{L}$. Combination of $\beta$-hCG with transvaginal ultrasonography is convenient and accurate. A limitation of this study was that the sample size was too small, and patients were only from 1 center. Our data suggests that the size of the FTP mass plays a less important role in the success rate of MTX treatment. Age might also be correlated with the outcome of MTX, but this needs to be clarified in further studies.

\section{Acknowledgments}

The authors would like to thank Dr. Dev Sooranna, Imperial College London, for editing the manuscript.

Funding: This study was supported by a grant from the National Natural Science Foundation of China (No. 81300513) and China National Key Research and development Grant (2018YFC1004600).

\section{Footnote}

Reporting Checklist: The authors have completed the STARD reporting checklist. Available at http://dx.doi.org/10.21037/ atm-20-7914 
Data Sharing Statement: Available at http://dx.doi. org/10.21037/atm-20-7914

Conflicts of Interest: All authors have completed the ICMJE uniform disclosure form (available at http://dx.doi. org/10.21037/atm-20-7914). The authors have no conflicts of interest to declare.

Ethical Statement: The authors are accountable for all aspects of the work in ensuring that questions related to the accuracy or integrity of any part of the work are appropriately investigated and resolved. All procedures performed in this study involving human participants were in accordance with the Declaration of Helsinki (as revised in 2013). The Ethics Committee of the IPMCH approved this study (No. 2013-6). Individual consent for this retrospective analysis was waived.

Open Access Statement: This is an Open Access article distributed in accordance with the Creative Commons Attribution-NonCommercial-NoDerivs 4.0 International License (CC BY-NC-ND 4.0), which permits the noncommercial replication and distribution of the article with the strict proviso that no changes or edits are made and the original work is properly cited (including links to both the formal publication through the relevant DOI and the license). See: https://creativecommons.org/licenses/by-nc-nd/4.0/.

\section{References}

1. Van Den Eeden SK, Shan J, Bruce C, et al. Ectopic pregnancy rate and treatment utilization in a large managed care organization. Obstet Gynecol 2005;105:1052-7.

2. Ustunyurt E, Duran M, Coskun E, et al. Role of initial and day 4 human chorionic gonadotropin levels in predicting the outcome of single-dose methotrexate treatment in women with tubal ectopic pregnancy. Arch Gynecol Obstet 2013;288:1149-52.

3. ACOG Practice Bulletin No. 191 Summary: Tubal Ectopic Pregnancy. Obstet Gynecol 2018;131:409-11.

4. Diagnosis and Management of Ectopic Pregnancy: Greentop Guideline No. 21. BJOG 2016;123:e15-e55.

5. Levin I, Tsafrir Z, Sa'ar N, et al. "Watchful waiting" in ectopic pregnancies: a balance between reduced success rates and less methotrexate. Fertil Steril 2011;95:1159-60.

6. Sowter MC, Farquhar CM, Petrie KJ, et al. A randomised trial comparing single dose systemic methotrexate and laparoscopic surgery for the treatment of unruptured tubal pregnancy. BJOG 2001;108:192-203.

7. Nama V, Manyonda I. Tubal ectopic pregnancy: diagnosis and management. Arch Gynecol Obstet. 2009;279:443-53.

8. Lipscomb GH, McCord ML, Stovall TG, et al. Predictors of success of methotrexate treatment in women with tubal ectopic pregnancies. N Engl J Med 1999;341:1974-8.

9. Tanaka T, Hayashi H, Kutsuzawa T, et al. Treatment of interstitial ectopic pregnancy with methotrexate: report of a successful case. Fertil Steril 1982;37:851-2.

10. Barnhart KT, Gosman G, Ashby R, et al. The medical management of ectopic pregnancy: a meta-analysis comparing "single dose" and "multidose" regimens. Obstet Gynecol 2003;101:778-84.

11. Yang C, Cai J, Geng Y, et al. Multiple-dose and doubledose versus single-dose administration of methotrexate for the treatment of ectopic pregnancy: a systematic review and meta-analysis. Reprod Biomed Online 2017;34:383-91.

12. Mol BW, Hajenius PJ, van der Veen F. Predictors of success of methotrexate treatment in women with tubal ectopic pregnancies. N Engl J Med 2000;342:1138.

13. Helmy S, Bader Y, Pablik E, et al. Cut-off value of initial serum $\beta$-hCG level predicting a successful MTX therapy in tubal ectopic pregnancy: a retrospective cohort study. Eur J Obstet Gynecol Reprod Biol 2014;179:175-80.

14. Helmy S, Koch M, Kölbl H, et al. Correlation of the volume of ectopic pregnancy and MTX therapy outcome: a retrospective cohort study. Eur J Obstet Gynecol Reprod Biol 2015;184:108-11.

15. Balci O, Ozdemir S, Mahmoud AS, et al. The efficacy of multiple-dose methotrexate treatment for unruptured tubal ectopic pregnancy and conversion rate to surgery: a study on 294 cases. Fertil Steril 2010;93:2415-7.

16. The effect of age and renal function on the efficacy and toxicity of methotrexate in rheumatoid arthritis. Rheumatoid Arthritis Clinical Trial Archive Group. J Rheumatol 1995;22:218-23.

17. Ferreri AJ, Guerra E, Regazzi M, et al. Area under the curve of methotrexate and creatinine clearance are outcome-determining factors in primary CNS lymphomas. Br J Cancer 2004;90:353-8.

(English Language Editor: C. Betlazar-Maseh)

Cite this article as: Lin Q, Lin N, Wang G, Zheng X, Hua R. A novel predict factor that increases the success rate of methotrexate treatment in fallopian tube pregnancy. Ann Transl Med 2021;9(2):146. doi: 10.21037/atm-20-7914 